\title{
AMP-activated protein kinase regulates thyroid hormone-stimulated osteocalcin synthesis in osteoblasts
}

\author{
AKIRA KONDO $^{1,2}$, TAKANOBU OTSUKA ${ }^{1}$, KENJI KATO $^{1,2}$, RIE MATSUSHIMA-NISHIWAKI $^{2}$, \\ GEN KUROYANAGI $^{1,2}$, JUN MIZUTANI ${ }^{1}$, HARUHIKO TOKUDA ${ }^{2,3}$ and OSAMU KOZAWA ${ }^{2}$ \\ ${ }^{1}$ Department of Orthopedic Surgery, Nagoya City University Graduate School of Medical Sciences, Nagoya 467-8601; \\ ${ }^{2}$ Department of Pharmacology, Gifu University Graduate School of Medicine, Gifu 501-1194; \\ ${ }^{3}$ Department of Clinical Laboratory, National Hospital for Geriatric Medicine, \\ National Center for Geriatrics and Gerontology, Obu, Aichi 474-8511, Japan
}

Received January 15, 2013; Accepted March 8, 2013

DOI: $10.3892 /$ ijmm.2013.1349

\begin{abstract}
AMP-activated protein kinase (AMPK) is recognized as a main regulator of energy homeostasis. Osteocalcin (OC), which is produced specifically by mature osteoblasts, is stored in bone matrix, strongly binds to hydroxyapatite and is released into the circulation, has been recognized as a marker of bone metabolism. It has recently been shown that $\mathrm{OC}$ released from osteoblasts influences energy metabolism as a hormone. We previously reported that triiodothyronine $\left(\mathrm{T}_{3}\right)$ stimulates the synthesis of OC in osteoblast-like MC3T3-E1 cells. In the present study, we investigated whether AMPK participates in $\mathrm{T}_{3}$-stimulated $\mathrm{OC}$ synthesis in osteoblasts. $\mathrm{T}_{3}$ time-dependently induced the phosphorylation of the AMPK $\alpha$-subunit (Thr-172), whereas $T_{3}$ failed to induce the phosphorylation of AMPK $\alpha$-subunit (Ser-485), AMPK $\beta$ subunit (Ser-108) and AMPK $\beta$-subunit (Ser-182). Both the release and the mRNA expression of $\mathrm{OC}$ induced by $\mathrm{T}_{3}$ were significantly inhibited by compound C, an AMPK inhibitor. Compound $\mathrm{C}$ suppressed the $\mathrm{T}_{3}$-induced phosphorylation of acetyl-CoA carboxylase, a direct substrate of AMPK. $\mathrm{T}_{3}$-stimulated OC release was significantly reduced in AMPKknockdown cells using AMPK-siRNA. These results strongly suggest that AMPK positively regulates $\mathrm{T}_{3}$-stimulated OC synthesis in osteoblasts.
\end{abstract}

\section{Introduction}

Bone metabolism is a highly coordinated process performed mainly by two types of functional cells, osteoblasts and osteoclasts. The former is responsible for bone formation and the latter for bone resorption. At present, it is well recognized

Correspondence to: Dr Haruhiko Tokuda, Department of Clinical Laboratory, National Hospital for Geriatric Medicine, National Center for Geriatrics and Gerontology, Obu, Aichi 474-8511, Japan E-mail: tokuda@ncgg.go.jp

Key words: thyroid hormone, AMP-activated protein kinase, osteocalcin, osteoblast that osteoblasts play a pivotal role in the regulation of bone resorption through receptor activator of nuclear factor- $\kappa \mathrm{B}$ ligand (RANKL) expression which is responsive to numerous bone resorptive stimuli (1). Osteoblasts, which are differentiated from mesenchymal progenitors, express various cell type-specific markers during the differentiation process. Osteocalcin (OC) is a bone-specific protein that is modified post-translationally by vitamin K-dependent $\gamma$-carboxylation, known as bone Gla-protein (2). It is well known that OC is synthesized specifically in osteoblasts; therefore, $\mathrm{OC}$ is recognized as one of the markers of the mature osteoblast phenotype. In contrast, OC-deficient mice reportedly display an increase in bone formation without impairing bone resorption, suggesting that $\mathrm{OC}$ is a determinant of moderate bone formation (3). In addition, it has recently been shown that un-carboxylated OC released from osteoblasts regulates energy metabolism through acting on pancreatic $\beta$-cells to increase insulin synthesis, adipocytes to increase adiponectin and skeletal myocytes to glucose uptake $(4,5)$. These findings lead us to speculate that bone, as an endocrine organ, plays a vital role also in energy metabolism through the release of OC. However, the exact mechanism underlying OC synthesis in osteoblasts remains to be clarified.

Thyroid hormone is an important regulator of skeletal function as well as whole body metabolism. Thyroid hormone excess, namely hyperthyroidism, is a major cause of secondary osteoporosis (6). In the state of hyperthyroidism, the serum levels of alkaline phosphatase and OC, markers of the osteoblast phenotype, are elevated as well as the excretion of pyridinoline and hydroxypyridinoline cross-link, which reflects bone resorption (6). It is known that an imbalance in bone remodeling causes the loss of bone mass by hyperthyroidism (6). The receptors for triiodothyronine $\left(\mathrm{T}_{3}\right)$, a member of the steroid hormone receptor superfamily, are expressed in osteoblasts (6). It has been reported that thyroid hormone stimulates alkaline phosphatase activity and secretion of $\mathrm{OC}$ and insulin-like growth factors in osteoblasts and that it modulates proliferation of osteoblasts (6-9). In our previous studies $(10,11)$, we reported that p38 mitogen-activated protein (MAP) kinase but not p44/p42 MAP kinase, is involved in 
the $\mathrm{T}_{3}$-stimulated OC synthesis in osteoblast-like MC3T3-E1 cells, and that the adenylyl cyclase-cAMP system has an inhibitory role in OC synthesis via suppression of $\mathrm{p} 38$ MAP kinase activation.

AMP-activated protein kinase (AMPK) is generally known to regulate multiple metabolic pathways (12). AMPK has emerged over the last decade as a key sensing mechanism in the regulation of cellular energy homeostasis (13-15). The enzyme is activated by a variety of physiological and pathological stresses which increase the intracellular AMP:ATP ratio, either by increasing ATP consumption or by decreasing ATP production in mammalian cells. Activated AMPK acts to restore cellular energy balance by ATP-generating pathways such as fatty acid oxidation, while simultaneously inhibiting ATP utilizing pathways. Regarding bone metabolism, metformin, which can activate AMPK (16), reportedly increases markers of osteoblast differentiation including OC mRNA expression, and enhances mineralization in osteoblastlike MC3T3-E1 cells (17). It has recently been reported that AMPK activation regulates bone formation and bone mass (18). These previous findings led us to speculate that AMPK influences bone metabolism through the functional modulation of osteoblasts. We previously demonstrated that AMPK plays a role in the synthesis of vascular endothelial growth factor or interleukin-6 in osteoblasts $(19,20)$. However, the exact role of AMPK in bone metabolism, particularly in osteoblasts, has not yet been fully elucidated.

In the present study, we investigated the mechanism behind $\mathrm{T}_{3}$-stimulated OC synthesis in osteoblast-like MC3T3-E1 cells and the involvement of AMPK in OC synthesis. We here demonstrated that AMPK positively regulates $\mathrm{T}_{3}$-stimulated OC synthesis in these cells.

\section{Materials and methods}

Materials. $\mathrm{T}_{3}$ was purchased from Sigma Chemical Co. (St. Louis, MO, USA). Mouse OC enzyme-linked immunosorbent assay (ELISA) kit was purchased from Biomedical Technologies, Inc. (Stoughton, MA, USA). Compound C, a pyrrazolopyrimidine derivative widely used as a specific and reversible AMPK inhibitor $(16,21,22)$, was purchased from Calbiochem-Novabiochem Corp. (La Jolla, CA, USA). Phospho-specific AMPK $\alpha$ (Thr-172) antibodies, phosphospecific AMPK $\alpha$ (Ser-485) antibodies, AMPK $\alpha$ antibodies, phospho-specific AMPK $\beta$ (Ser-108) antibodies, phosphospecific AMPK $\beta$ (Ser-182) antibodies, AMPK $\beta$ antibodies and phospho-specific acetyl-CoA carboxylase antibodies were purchased from Cell Signaling Technology, Inc. (Beverly, MA, USA). GAPDH antibodies were obtained from Santa Cruz Biotechnology, Inc. (Santa Cruz, CA, USA). An ECL Western blotting detection system was purchased from GE Healthcare, Ltd. (Buckinghamshire, UK). Control short interfering RNA (siRNA; Silencer Negative Control no. 1 siRNA) and AMPK-siRNA were purchased from Qiagen (Hilden, Germany). siLentFect was purchased from Bio-Rad (Hercules, CA, USA). TRIzol reagent and Omniscript Reverse Transcriptase kit were purchased from Invitrogen (Carlsbad, CA, USA) and Qiagen, respectively. Fast-start DNA Master SYBR-Green I was purchased from Roche Diagnostics GmbH (Mannheim, Germany). Other materials and chemicals were obtained from commercial sources. Compound $\mathrm{C}$ was dissolved in dimethyl sulfoxide. The maximum concentration of dimethyl sulfoxide was $0.1 \%$, which did not affect the assay for OC or detection of the protein level by western blot analysis.

Cell culture. Cloned osteoblast-like MC3T3-E1 cells derived from newborn mouse calvaria (23) were maintained as previously described (24). Briefly, the cells were cultured in $\alpha$-minimum essential medium ( $\alpha$-MEM) containing $10 \%$ fetal calf serum (FCS) at $37^{\circ} \mathrm{C}$ in a humidified atmosphere of $5 \%$ $\mathrm{CO}_{2} / 95 \%$ air. The cells were seeded into $35-\mathrm{mm}\left(5 \times 10^{4}\right)$ or $90-\mathrm{mm}\left(2 \times 10^{5}\right)$ diameter dishes in $\alpha$-MEM containing $10 \%$ FCS. After 5 days, the medium was exchanged for $\alpha$-MEM containing $0.3 \%$ FCS. The cells were used for experiments after $48 \mathrm{~h}$.

OC assay. The cultured cells were stimulated by $\mathrm{T}_{3}$ in $1 \mathrm{ml}$ of $\alpha$-MEM containing $0.3 \%$ FCS for the indicated periods. The conditioned medium was collected at the end of the incubation, and the OC concentration was measured by an OC ELISA kit. When indicated, the cells were pretreated with various doses of compound $\mathrm{C}$ for $60 \mathrm{~min}$.

Western blot analysis. Western blot analysis was performed as previously described (25). The cultured cells were stimulated by $\mathrm{T}_{3}$ or vehicle in $\alpha$-MEM containing $0.3 \%$ FCS for the indicated periods. When indicated, the cells were pretreated with various doses of compound $\mathrm{C}$ for $60 \mathrm{~min}$. The cells were washed twice with phosphate-buffered saline and then lysed, homogenized and sonicated in a lysis buffer containing $62.5 \mathrm{mM}$ Tris/ $\mathrm{HCl} ; \mathrm{pH}$ 6.8,3\% sodium dodecyl sulfate (SDS), $50 \mathrm{mM}$ dithiothreitol and 10\% glycerol. SDS-polyacrylamide gel electrophoresis (PAGE) was performed according to Laemmli (26) on $10 \%$ polyacrylamide gel. The protein was fractionated and transferred onto Immun-Blot PVDF membranes (Bio-Rad). Membranes were blocked with 5\% fat-free dry milk in Tris-buffered saline-Tween-20 (TBS-T; $20 \mathrm{mM}$ Tris/HCl, pH 7.6, $137 \mathrm{mM} \mathrm{NaCl}, 0.1 \%$ Tween-20) for $2 \mathrm{~h}$ before incubation with the primary antibodies. The following antibodies were used: phospho-specific AMPK $\alpha$ (Thr-172) antibodies, phospho-specific AMPK $\alpha$ (Ser-485) antibodies, AMPK $\alpha$ antibodies, phospho-specific AMPK $\beta$ (Ser-108) antibodies, phospho-specific AMPK $\beta$ (Ser-182) antibodies, AMPK $\beta$ antibodies, phospho-specific acetyl-CoA carboxylase antibodies and GAPDH antibodies as primary antibodies. Peroxidase-labeled antibodies raised in goat against rabbit IgG [Kirkegaard \& Perry Laboratories (KPL), Inc., Gaithersburg, MD, USA] were used as secondary antibodies. The primary and secondary antibodies were diluted at 1:1,000 with 5\% fatfree dry milk in TBS-T. Peroxidase activity on the membrane was visualized on X-ray film by means of the ECL Western blotting detection system.

Real-time RT-PCR. The cultured cells were pretreated with compound $\mathrm{C}$ for $60 \mathrm{~min}$ and stimulated by $\mathrm{T}_{3}$ for the indicated periods. Total RNA was isolated and transcribed into cDNA using TRIzol reagent and Omniscript Reverse Transcriptase kit. Real-time RT-PCR was performed using a LightCycler system (Roche Diagnostics) in capillaries and Fast-Start DNA Master SYBR-Green I provided with the kit. Sense and 


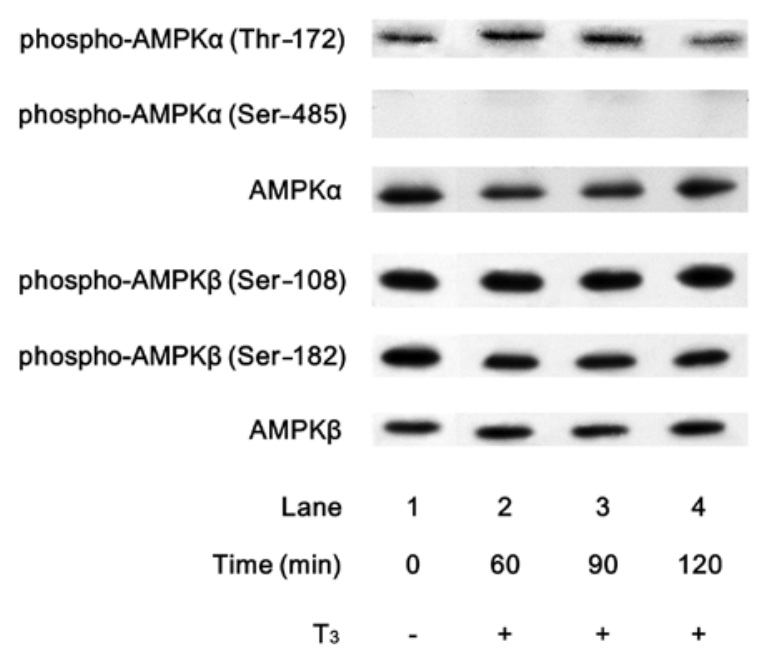

Figure 1. Effects of $\mathrm{T}_{3}$ on the phosphorylation of AMPK in MC3T3-E1 cells. The cultured cells were stimulated by $10 \mathrm{nM} \mathrm{T}_{3}$ for the indicated periods. The extracts of cells were subjected to SDS-PAGE with subsequent western blot analysis with antibodies against phospho-specific AMPK $\alpha$ (Thr-172), phospho-specific AMPK $\alpha$ (Ser-485), AMPK $\alpha$, phospho-specific AMPK $\beta$ (Ser-108), phospho-specific AMPK $\beta$ (Ser-182) or AMPK $\beta$.

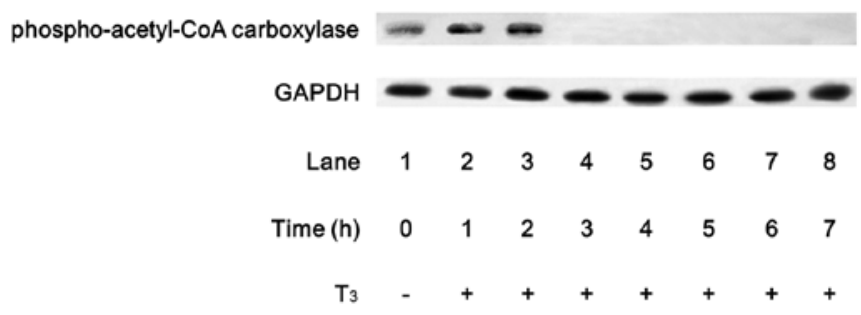

Figure 2. Effect of $\mathrm{T}_{3}$ on the phosphorylation of acetyl-CoA carboxylase in MC3T3-E1 cells. The cultured cells were stimulated by $10 \mathrm{nM} \mathrm{T}_{3}$ for the indicated periods. The extracts of cells were subjected to SDS-PAGE with subsequent western blot analysis with antibodies against phospho-specific acetyl-CoA carboxylase or GAPDH.

antisense primers were synthesized based on the report of Zhang et al (27) for mouse OC mRNA and GAPDH mRNA. The amplified products were determined by melting curve analysis and agarose electrophoresis. OC mRNA levels were normalized with those of GAPDH mRNA.

siRNA transfection. To knockdown AMPK in MC3T3-E1 cells, the cells were transfected with negative control siRNA or AMPK-siRNA utilizing siLentFect according to the manufacturer's protocol. In brief, the cells $\left(1 \times 10^{5}\right.$ cells) were seeded into 35-mm diameter dishes in $\alpha$-MEM containing $10 \%$ FCS and subcultured for $48 \mathrm{~h}$. The cells were then incubated at $37^{\circ} \mathrm{C}$ with $50 \mathrm{nM}$ siRNA-siLentFect complexes. After $24 \mathrm{~h}$, the medium was replaced with $\alpha$-MEM containing $0.3 \%$ FCS The cells were then stimulated by $\mathrm{T}_{3}$ in $\alpha$-MEM containing $0.3 \%$ FCS for the indicated periods.

Determination of the enzyme activation. The absorbance of enzyme immunoassay samples was measured at $450 \mathrm{~nm}$ using the EL340 Bio Kinetic Reader (Bio-Tek Instruments, Inc., Winooski, VT, USA).

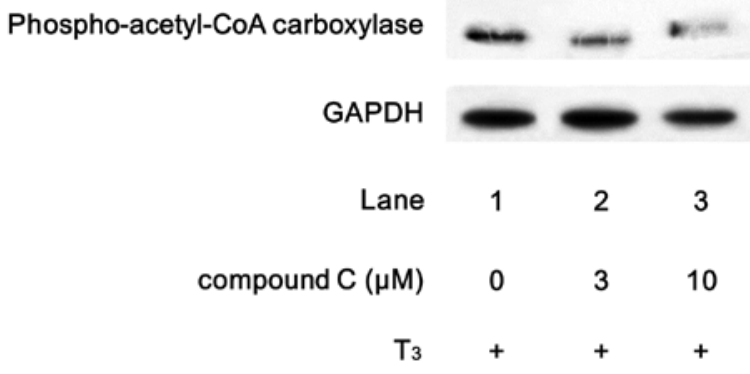

Figure 3. Effect of compound $\mathrm{C}$ on the $\mathrm{T}_{3}$-induced phosphorylation of acetylCoA carboxylase in MC3T3-E1 cells. The cultured cells were pretreated with various doses of compound $\mathrm{C}$ for $60 \mathrm{~min}$, and then stimulated by $10 \mathrm{nM} \mathrm{T}_{3}$ for $60 \mathrm{~min}$. The extracts of cells were subjected to SDS-PAGE with subsequent western blot analysis with antibodies against phospho-specific acetyl-CoA carboxylase or GAPDH.

Statistical analysis. The data were analyzed by ANOVA followed by the Bonferroni method for multiple comparisons between pairs, and a $\mathrm{P}<0.05$ was considered to indicate a statistically significant result. All data are presented as the means \pm SEM of triplicate independent determinations.

\section{Results}

Effects of $T_{3}$ on the phosphorylation of AMPK in MC3T3-E1 cells. In order to investigate whether $\mathrm{T}_{3}$ activates AMPK in osteoblasts, we first examined the effects of $\mathrm{T}_{3}$ on the phosphorylation of AMPK in osteoblast-like MC3T3-E1 cells. $\mathrm{T}_{3}$ markedly induced the phosphorylation of the AMPK $\alpha$-subunit (Thr-172) (Fig. 1). The effect of $\mathrm{T}_{3}$ on the phosphorylation of the AMPK $\alpha$-subunit (Thr-172) reached its peak at 60-90 min and decreased thereafter. However, $\mathrm{T}_{3}$ failed to affect the phosphorylation levels of AMPK $\alpha$-subunit (Ser-485), AMPK $\beta$ subunit (Ser-108) and AMPK $\beta$-subunit (Ser-182) (Fig. 1).

Effect of compound $C$ on the phosphorylation of acetyl-CoA carboxylase in MC3T3-E1 cells. It is generally recognized that acetyl-CoA carboxylase, which catalyzes an important step in lipid synthesis, is a direct substrate of AMPK (15). We confirmed that $\mathrm{T}_{3}$ markedly stimulated the phosphorylation of acetyl-CoA carboxylase in MC3T3-E1 cells (Fig. 2). The effect of $\mathrm{T}_{3}$ on the acetyl-CoA carboxylase phosphorylation reached its peak within $2 \mathrm{~h}$ and decreased thereafter. We found that compound C, an inhibitor of AMPK (16), markedly suppressed the $\mathrm{T}_{3}$-stimulated phosphorylation of acetyl-CoA carboxylase (Fig. 3).

Effect of compound $C$ on the $T_{3}$-stimulated $O C$ release in MC3T3-E1 cells. In order to clarify the involvement of AMPK in the $\mathrm{T}_{3}$-stimulated $\mathrm{OC}$ release in osteoblasts, we next examined the effect of compound $\mathrm{C}$ on the release of $\mathrm{OC}$ stimulated by $\mathrm{T}_{3}$ in MC3T3-E1 cells. Compound $\mathrm{C}$, which alone did not affect the OC levels, significantly suppressed the $\mathrm{T}_{3}$-stimulated OC release in a time-dependent manner (Fig. 4). The inhibitory effect of compound $\mathrm{C}$ was dose-dependent in the range between 0.3 and $10 \mu \mathrm{M}$ (Fig. 5). The maximum effect of compound $\mathrm{C}$ was observed at $10 \mu \mathrm{M}$, which resulted in $\sim 90 \%$ inhibition compared to the $\mathrm{OC}$ level with $\mathrm{T}_{3}$ alone. 


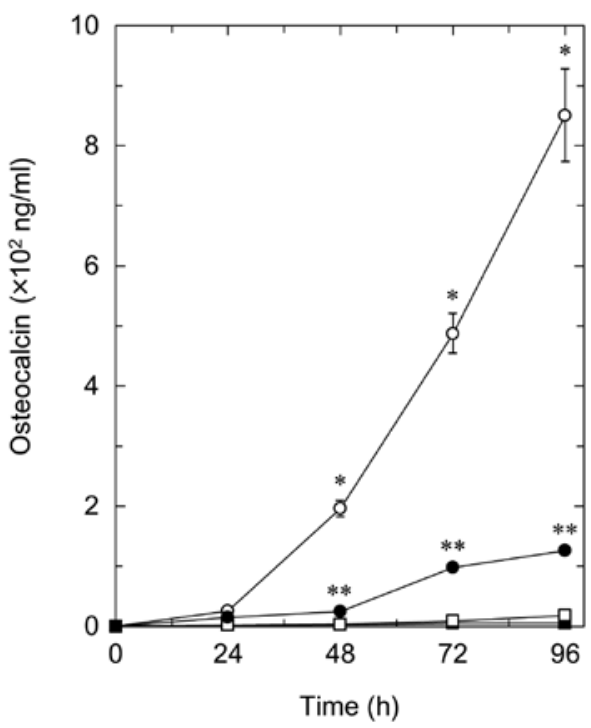

Figure 4. Effect of compound $\mathrm{C}$ on $\mathrm{T}_{3}$-stimulated OC release in MC3T3-E1 cells. The cultured cells were pretreated with $10 \mu \mathrm{M}$ of compound $\mathrm{C}$ (closed symbols) or vehicle (open symbols) for $60 \mathrm{~min}$, and then stimulated by $10 \mathrm{nM}$ $\mathrm{T}_{3}$ (circles) or vehicle (squares) for the indicated periods. Each value represents the mean \pm SEM of triplicate independent determinations. Similar results were obtained with two additional and different cell preparations. ${ }^{*} \mathrm{P}<0.05$, compared to the value of control; ${ }^{* *} \mathrm{P}<0.05$, compared to the value of $\mathrm{T}_{3}$ alone.

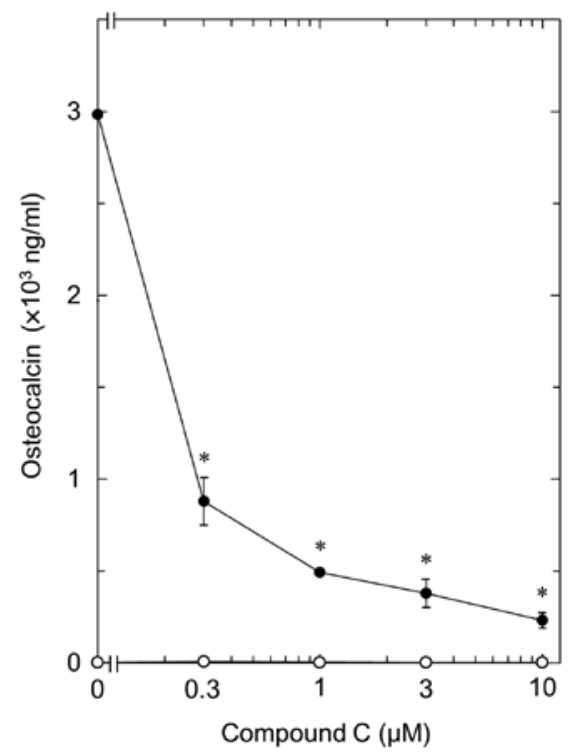

Figure 5. Dose-dependent effect of compound $\mathrm{C}$ on $\mathrm{T}_{3}$-stimulated $\mathrm{OC}$ release in MC3T3-E1 cells. The cultured cells were pretreated with various doses of compound $\mathrm{C}$ for $60 \mathrm{~min}$, and then stimulated by $10 \mathrm{nM} \mathrm{T}_{3}(\bullet)$ or vehicle (O) for $96 \mathrm{~h}$. Each value represents the mean \pm SEM of triplicate independent determinations. Similar results were obtained with two additional and different cell preparations. ${ }^{\text {}} \mathrm{P}<0.05$, compared to the value of $\mathrm{T}_{3}$ alone.

Effect of compound $C$ on the $T_{3}$-induced $O C$ mRNA expression in MC3T3-El cells. It has been shown that $\mathrm{T}_{3}$ induces the mRNA expression of OC in osteoblasts (9). In order to investigate whether the suppression of $\mathrm{T}_{3}$-stimulated $\mathrm{OC}$ synthesis by compound $\mathrm{C}$ is mediated through transcriptional events, we next examined the effect of compound $\mathrm{C}$ on $\mathrm{T}_{3}$-induced OC mRNA expression. Compound $\mathrm{C}$, which by itself had little

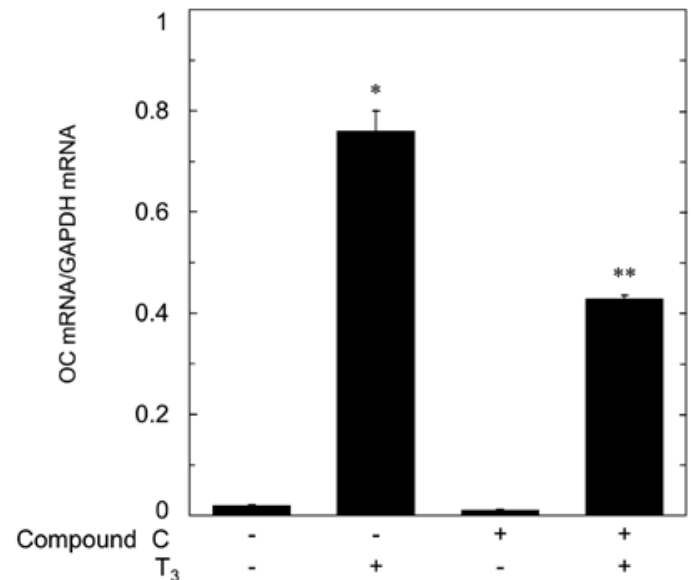

Figure 6. Effect of compound $\mathrm{C}$ on $\mathrm{T}_{3}$-induced $\mathrm{OC}$ mRNA expression in MC3T3-E1 cells. The cultured cells were pretreated with $10 \mu \mathrm{M}$ compound C or vehicle for $60 \mathrm{~min}$, and then stimulated by $10 \mathrm{nM} \mathrm{T}_{3}$ or vehicle for $48 \mathrm{~h}$. Total RNA was isolated and transcribed into cDNA. The expression of OC mRNA and GAPDH mRNA was quantified by real-time RT-PCR. OC mRNA levels were normalized with those of GAPDH mRNA. Each value represents the mean \pm SEM of triplicate independent determinations. Similar results were obtained with two additional and different cell preparations. " $\mathrm{P}<0.05$, compared to the value of control; ${ }^{* *} \mathrm{P}<0.05$, compared to the value of $\mathrm{T}_{3}$ alone.

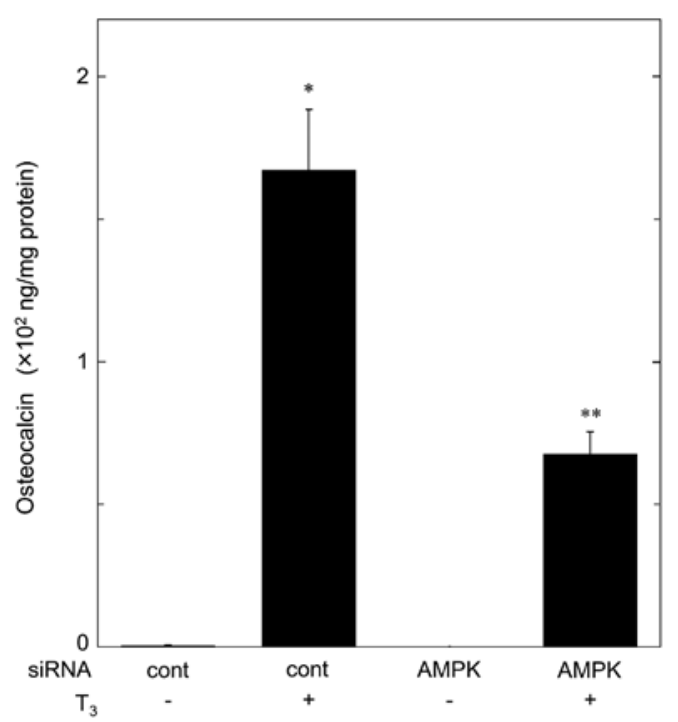

Figure 7. Effect of AMPK siRNA on the $\mathrm{T}_{3}$-stimulated OC release in MC3T3-E1 cells. The cultured cells were transfected with $50 \mathrm{nM}$ control siRNA (cont) or 50 nM AMPK-siRNA (siRNA Mm_Prkaa1_1 Qiagen) by using the siLentFect. Forty-eight hours after transfection, the cells were stimulated by $10 \mathrm{nM} \mathrm{T}_{3}$ or vehicle for another $96 \mathrm{~h}$. OC concentrations of the culture medium were determined by ELISA. The osteocalcin level was corrected for the total protein level. Each value represents the mean \pm SEM of triplicate independent determinations. ${ }^{*} \mathrm{P}<0.05$, compared to the value of vehicle with control siRNA transfection; ${ }^{* *} \mathrm{P}<0.05$, compared to the value of $\mathrm{T}_{3}$ with control siRNA transfection.

effect on the basal level of OC mRNA, significantly reduced the $\mathrm{T}_{3}$-induced level of OC mRNA (Fig. 6).

Effect of AMPK-siRNA on $T_{3}$-stimulated $O C$ release in MC3T3-E1 cells. We further investigated the effect of AMPK knockdown on the OC release stimulated by $\mathrm{T}_{3}$ in MC3T3-E1 cells. In comparison with the control cells, the $\mathrm{T}_{3}$-stimulated OC release was significantly diminished in AMPK-knockdown 
cells by AMPK-siRNA (Fig. 7). Approximately $60 \%$ suppression of the $\mathrm{T}_{3}$-stimulated $\mathrm{OC}$ release resulted following the treatment with AMPK-siRNA.

\section{Discussion}

In the present study, we showed that $\mathrm{T}_{3}$ induced the phosphorylation of AMPK in osteoblast-like MC3T3-E1 cells, using phospho-specific AMPK $\alpha$-subunit (Thr-172) antibodies. It is generally recognized that the phosphorylation of Thr-172 in the AMPK $\alpha$-subunit is necessary for AMPK activity $(12,28)$. Therefore, it is likely that $\mathrm{T}_{3}$ stimulates the activation of AMPK in osteoblast-like MC3T3-E1 cells. To the best of our knowledge, this is probably the first report showing the involvement of AMPK in the intracellular signaling of $\mathrm{T}_{3}$ in osteoblasts. On the other hand, $\mathrm{T}_{3}$ failed to induce the phosphorylation of AMPK $\alpha$-subunit (Ser-485). It seems unlikely that the phosphorylation of Ser-485 in the $\alpha$-subunit is involved in $\mathrm{T}_{3}$-induced AMPK activation in MC3T3-E1 cells. In addition, we found that AMPK $\beta$-subunits (Ser-108 and Ser-182), which were phosphorylated without stimulation, were barely affected by $T_{3}$. It has been shown that phosphorylation at Ser-108 of the AMPK $\beta$-subunit is required for the activation of AMPK, while phosphorylation of Ser-182 affects AMPK localization (29). Moreover, we showed here that the phosphorylation of acetyl-CoA carboxylase, known as a direct substrate of AMPK (30), was significantly induced by $\mathrm{T}_{3}$. The time course of the phosphorylation of AMPK $\alpha$-subunit (Thr-172) stimulated by $\mathrm{T}_{3}$ appears to be more rapid than that of acetyl-CoA carboxylase. Furthermore, we found that compound $\mathrm{C}$, an AMPK inhibitor (16), reduced the phosphorylation levels of acetyl-CoA carboxylase by $\mathrm{T}_{3}$. It is probable that the inhibitory effect of compound $\mathrm{C}$ is exerted through the suppression of AMPK. Based on our findings, it is most likely that $\mathrm{T}_{3}$ positively regulates AMPK activity via the phosphorylation of the AMPKa-subunit (Thr-172) in osteoblast-like MC3T3-E1 cells.

We previously demonstrated that $\mathrm{T}_{3}$ induces OC synthesis which is a marker of osteoblast differentiation in osteoblast-like MC3T3-E1 cells $(10,11)$. Thus, we next investigated whether or not AMPK is involved in the $\mathrm{T}_{3}$-stimulated OC synthesis in MC3T3-E1 cells. We showed that the $\mathrm{T}_{3}$-stimulated OC release was significantly suppressed by compound $\mathrm{C}$, an inhibitor of AMPK (16), suggesting that AMPK is involved in the OC release induced by $\mathrm{T}_{3}$ in these cells. Additionally, compound $\mathrm{C}$ markedly reduced the OC mRNA expression induced by $\mathrm{T}_{3}$, suggesting that AMPK regulates OC synthesis at a point upstream of the transcriptional process. We further examined the effect of AMPK knockdown by siRNA on $\mathrm{T}_{3}$-stimulated OC release and demonstrated the concomitant reduction in $\mathrm{T}_{3}$-stimulated induction of OC by AMPK knockdown in the osteoblast-like MC3T3-E1 cells. Taking our findings into account, it is most likely that AMPK functions as a positive regulator in $\mathrm{T}_{3}$-stimulated $\mathrm{OC}$ synthesis in osteoblasts.

Thyroid hormone excess, or hyperthyroidism, is a major cause of secondary osteoporosis. Both bone formation and bone resorption are accelerated in the state of hyperthyroidism, and the predominance of bone resorption rather than bone formation results in the loss of bone mass (6). On the other hand, deficiency of the thyroid hormone causes severe skeletal growth retardation in infants. These clinical states indicate the importance of the thyroid hormone in bone metabolism. Thus, it is essential to clarify the precise mechanism of $T_{3}$ action, an active form of thyroid hormone, particularly in osteoblasts which promote bone formation and regulate bone resorption. OC, a $\gamma$-carboxylated calcium-binding protein, is generally recognized to be produced by mature osteoblasts (2). It is well known that the serum level of OC is elevated in patients with hyperthyroidism (6). OC-deficient mice reportedly develop hyperostosis (3), suggesting its crucial role in the bone remodeling process. Thus, our present findings demonstrating the AMPK-dependent $\mathrm{OC}$ release induced by $\mathrm{T}_{3}$ provide a new concept of bone metabolism. In addition, it has recently been shown that un-carboxylated OC released from osteoblasts as a bone-derived hormone regulates energy metabolism by acting on pancreatic $\beta$-cells to increase insulin synthesis, on adipocytes to increase adiponectin and on skeletal myocytes for glucose uptake in rodent $(4,5)$. This significant effect of un-carboxylated $\mathrm{OC}$ has not yet been clarified in human; however, osteoblast-releasing OC may participate in whole body energy regulation. In addition, metformin, an AMPKactivating substance, has already been widely used as an agent for diabetes. AMPK plays a vital role as an energy sensor promoting the development of tissue derived from mesenchymal cells such as muscle and bone. Taking our present findings into account as a whole, AMPK regulation of OC release by osteoblasts may be a therapeutic target for metabolic disorders. Further investigation is required to clarify the details of AMPK in bone metabolism. In conclusion, our results strongly suggest that AMPK positively regulates $\mathrm{T}_{3}$-stimulated OC synthesis in osteoblasts.

\section{Acknowledgements}

We are very grateful to Emiko Fuseya and Yumiko Kurokawa for their skillful technical assistance. This investigation was supported in part by a Grant-in-Aid for Scientific Research (16590873 and 16591482) from the Ministry of Education, Science, Sports and Culture of Japan and the Research Funding for Longevity Sciences (21A-4 and 22A-22) from the National Center for Geriatrics and Gerontology (NCGG), Japan.

\section{References}

1. Boyce BF and Xing L: Functions of RANKL/RANK/OPG in bone modeling and remodeling. Arch Biochem Biophys 473: 139-146, 2008.

2. Hauschka PV, Lian JB, Cole DE and Gundberg CM: Osteocalcin and matrix Gla protein: vitamin K-dependent proteins in bone. Physiol Rev 69: 990-1047, 1989.

3. Ducy P, Desbois C, Boyce B, Pinero G, Story B, Dunstan C, Smith E, Bonadio J, Goldstein S, Gundberg C, Bradley A and Karsenty G: Increased bone formation in osteocalcin-deficient mice. Nature 382: 448-452, 1996.

4. Lee NK and Karsenty G: Reciprocal regulation of bone and energy metabolism. Trends Endocrinol Metab 19: 161-166, 2008.

5. Rosen CJ: Bone remodeling, energy metabolism, and the molecular clock. Cell Metab 7: 7-10, 2008.

6. Gogakos AI, Duncan Bassett JH and Williams GR: Thyroid and bone. Arch Biochem Biophys 503: 129-136, 2010.

7. Rizzoli R, Poser J and Burgi U: Nuclear thyroid hormone receptors in cultured bone cells. Metabolism 35: 71-74, 1986.

8. Kasono K, Sato K, Han DC, Fujii Y, Tsushima T and Shizume K: Stimulation of alkaline phosphatase activity by thyroid hormone in mouse osteoblast-like cells (MC3T3-E1): a possible mechanism of hyperalkaline phosphatasia in hyperthyroidism. Bone Miner 4: 355-363, 1988. 
9. Kassem M, Mosekilde L and Eriksen EF: Effects of triiodothyronine on DNA synthesis and differentiation markers of normal human osteoblast-like cells in vitro. Biochem Mol Biol Int 30: 779-788, 1993.

10. Ishisaki A, Tokuda H, Yoshida M, Hirade K, Kunieda K, Hatakeyama D, Shibata T and Kozawa O: Activation of p38 mitogen-activated protein kinase mediates thyroid hormonestimulated osteocalcin synthesis in osteoblasts. Mol Cell Endocrinol 214: 189-195, 2004.

11. Kanno Y, Ishisaki A, Yoshida M, Nakajima K, Tokuda H, Numata $\mathrm{O}$ and Kozawa O. Adenylyl cyclase-cAMP system inhibits thyroid hormone-stimulated osteocalcin synthesis in osteoblasts. Mol Cell Endocrinol 229: 75-82, 2005.

12. Fogarty S and Hardie DG: Development of protein kinase activators: AMPK as a target in metabolic disorders and cancer. Biochim Biophys Acta 1804: 581-591, 2010.

13. Hardie DG, Hawley SA and Scott JW: AMP-activated protein kinase - development of the energy sensor concept. J Physiol 574 7-15, 2006.

14. Lage R, Dieguez C, Vidal-Puig A and Lopez M: AMPK: a metabolic gauge regulating whole-body energy homeostasis. Trends Mol Med 14: 539-549, 2008.

15. Steinberg GR and Kemp BE: AMPK in health and disease. Physiol Rev 89: 1025-1078, 2009.

16. Zhou G, Myers R, Li Y, Chen Y, Shen X, Fenyk-Melody J, Wu M, Ventre J, Doebber T, Fujii N, Musi N, Hirshman MF, Goodyear LJ and Moller DE: Role of AMP-activated protein kinase in mechanism of metformin action. J Clin Invest 108 : $1167-1174,2001$

17. Kanazawa I, Yamaguchi T, Yano S, Yamauchi M and Sugimoto T: Metformin enhances the differentiation and mineralization of osteoblastic MC3T3-E1 cells via AMP kinase activation as well as eNOS and BMP-2 expression. Biochem Biophys Res Commun 375: 414-419, 2008.

18. Shah M, Kola B, Bataveljic A, Arnett TR, Viollet B, Saxon L, Korbonits $\mathrm{M}$ and Chenu C: AMP-activated protein kinase (AMPK) activation regulates in vitro bone formation and bone mass. Bone 47: 309-319, 2010.

19. Kato K, Tokuda H, Adachi S, Matsushima-Nishiwaki R, Natsume H, Yamakawa K, Gu Y, Otsuka T and Kozawa O: AMP-activated protein kinase positively regulates FGF-2stimulated VEGF synthesis in osteoblasts. Biochem Biophys Res Commun 400: 123-127, 2010.

20. Kato K, Otsuka T, Kondo A, Matsushima-Nishiwaki R, Natsume H, Kozawa $\mathrm{O}$ and Tokuda H: AMP-activated protein kinase regulates PDGF-BB-stimulated interleukin-6 synthesis in osteoblasts: involvement of mitogen-activated protein kinases. Life Sci 90: 71-76, 2012.
21. Kim EK, Miller I, Aja S, Landree LE, Pinn M, McFadden J, Kuhajda FP, Moran TH and Ronnett GV: C75, a fatty acid synthase inhibitor, reduces food intake via hypothalamic AMP-activated protein kinase. J Biol Chem 279: 19970-19976, 2004.

22. Nam M, Lee WH, Bae EJ and Kim SG: Compound C inhibits clonal expansion of preadipocytes by increasing p21 level irrespectively of AMPK inhibition. Arch Biochem Biophys 479: 74-81, 2008.

23. Sudo H, Kodama HA, Amagai Y, Yamamoto S and Kasai S: In vitro differentiation and calcification in a new clonal osteogenic cell line derived from newborn mouse calvaria. J Cell Biol 96: 191-198, 1983.

24. Kozawa O, Tokuda H, Miwa M, Kotoyori J and Oiso Y: Cross-talk regulation between cyclic AMP production and phosphoinositide hydrolysis induced by prostaglandin $\mathrm{E}_{2}$ in osteoblast-like cells. Exp Cell Res 198: 130-134, 1992.

25. Kato $\mathrm{K}$, Ito $\mathrm{H}$, Hasegawa $\mathrm{K}$, Inaguma $\mathrm{Y}$, Kozawa $\mathrm{O}$ and Asano T: Modulation of the stress-induced synthesis of hsp27 and alpha B-crystallin by cyclic AMP in C6 rat glioma cells. J Neurochem 66: 946-950, 1996.

26. Laemmli UK: Cleavage of structural proteins during the assembly of the head of bacteriophage T4. Nature 227: 680-685, 1970.

27. Zhang W, Yang N and Shi XM: Regulation of mesenchymal stem cell osteogenic differentiation by glucocorticoid-induced leucine zipper (GILZ). J Biol Chem 283: 4723-4729, 2008.

28. Hawley SA, Davison M, Woods A, Davies SP, Beri RK, Carling D and Hardie DG: Characterization of the AMP-activated protein kinase kinase from rat liver and identification of threonine 172 as the major site at which it phosphorylates AMP-activated protein kinase. J Biol Chem 271: 27879-27887, 1996.

29. Warden SM, Richardson C, O'Donnell J Jr, Stapleton D, Kemp BE and Witters LA: Post-translational modifications of the beta-1 subunit of AMP-activated protein kinase affect enzyme activity and cellular localization. Biochem J 354: 275-283, 2001.

30. Park SH, Gammon SR, Knippers JD, Paulsen SR, Rubink DS and Winder WW: Phosphorylation-activity relationships of AMPK and acetyl-CoA carboxylase in muscle. J Appl Physiol 92: 2475-2482, 2002. 